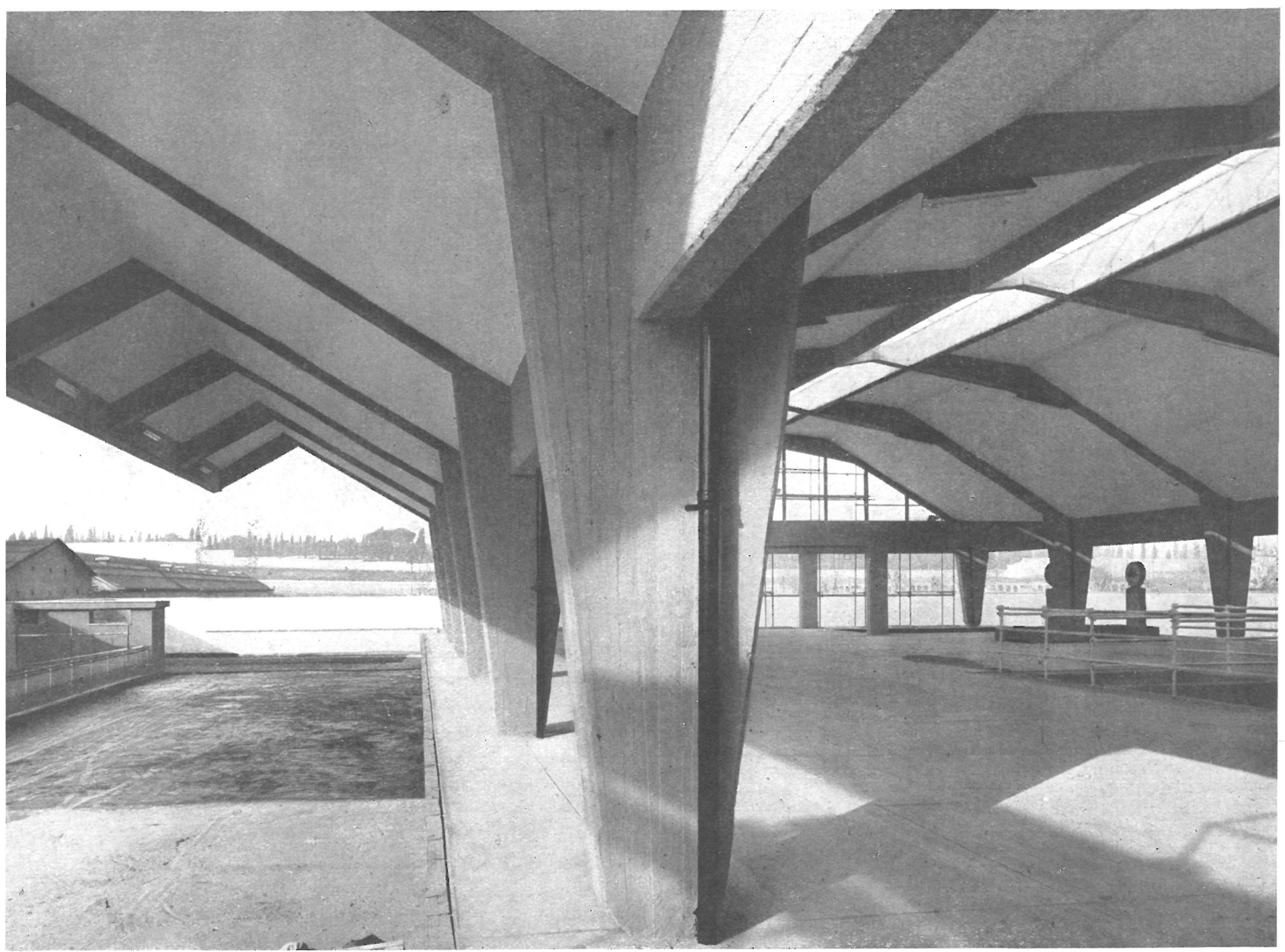

$831-19$

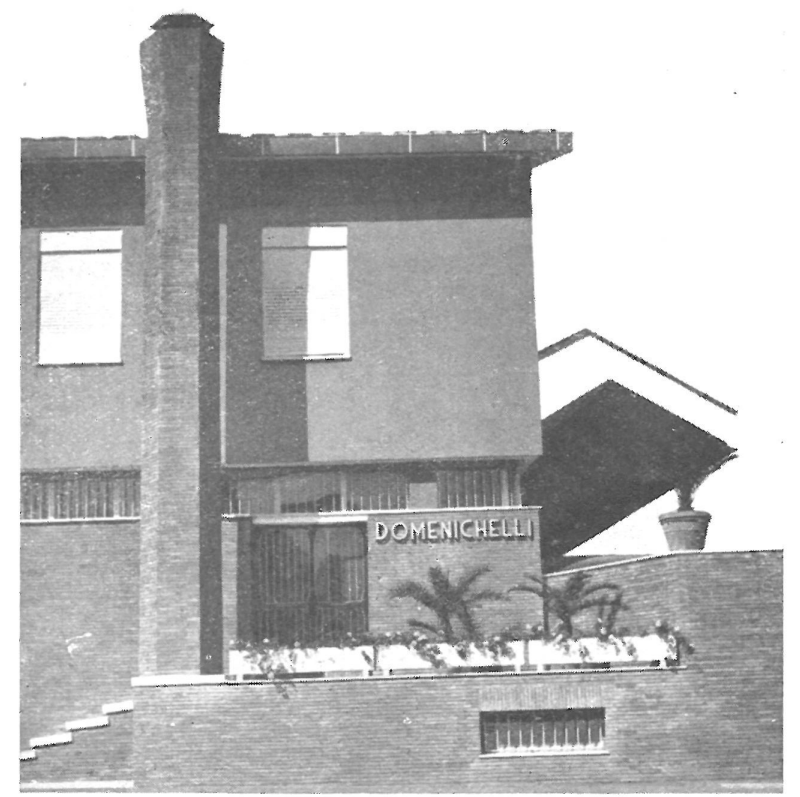

\title{
almacén de mercancías
}

LUIGI VAGNETTI, arquitecto FRANCO PIRO, ingeniero

Documentación amablemente facilitada por nuestro corresponsal en Italia, el arquitecto Sandro Giannini

INFORMES DE LA CONSTRUCCION 97 
Perspectiva del conjunto y fachada principal.

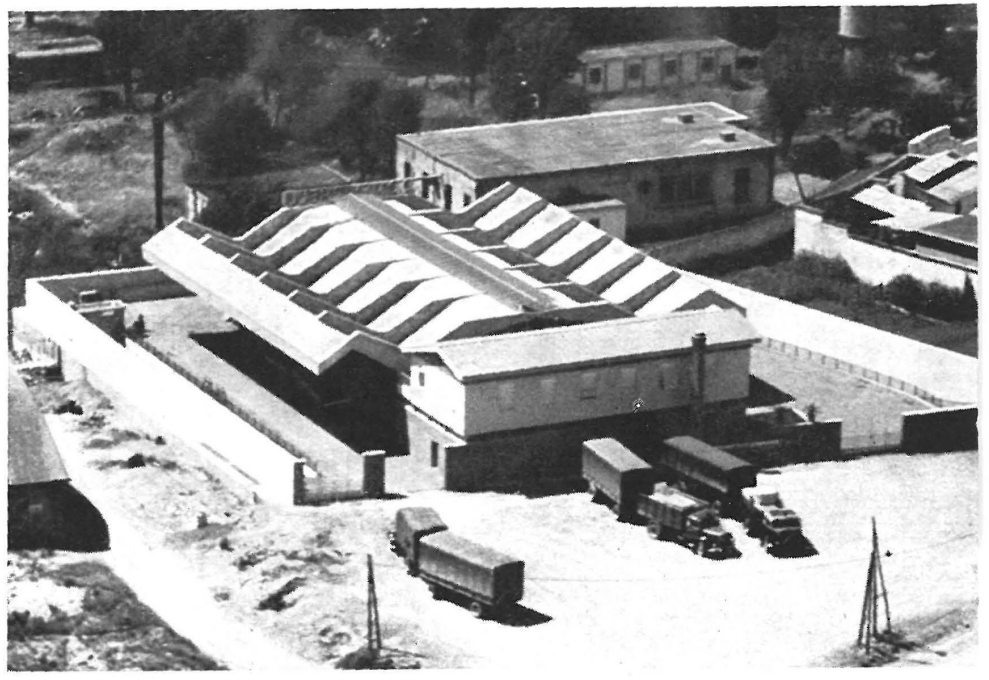

Esta obra hace patente un problema con el que muy frecuentemente han de enfrentarse los arquitectos e ingenieros dotados de un especial instinto y deseo de creación, conscientes de la necesidad de añadir algo a la pura realización funcional de la construcción. Y no es más que el contraste que surge al tener que compaginarse dos elementos, inevitablemente algo distintos, como son las exigencias de la obra en sí o de su dueño con la concepción del proyectista.

Luigi Vagnetti es un arquitecto que cree en la arquitectura moderna; pero insiste en su proveniencia, a través de una continuidad legítima, de la clásica. Creer esto no significa despreciar la realidad en que nos movemos. Es simplemente dotar a nuestras realizaciones de las características que en las clásicas fueron las bases de su valor. Y, como señala acertadamente Sandro Giannini en su artículo sobre la obra que nos ocupa, si elementos como el arco y la columna, de significación puramente estructural en el clasicismo, fueron elevados a objeto artístico, lo correspondiente hoy, en la intención de Vagnetti, sería dotar de calidad artística a nuestros eiementos estáticos. En esta constitución de la forma estructural, estriba la idea del arquitecto.

Ahora bien, hacer esto exige todavía sacrificios y compromisos. Las exigencias comerciales de la obra no siempre están conscientes de todo lo que significa, $\mathrm{Y}$ aquí está el motivo por el que Giannini señala que este edificio haya tenido solamente el que Giannini señala que este edificio haya tenido solamente
un éxito parcial. El arquitecto ha debido fracturar mucho su un éxito parcial. El arquitecto ha debido fracturar mucho su
postura artística para atenerse fielmente al programa estructural. Con todo, la suave crítica mencionada no está exenta de admiracion con el esfuerzo realizado en el proyecto para conseguir esta acomodación, que es el objetivo final. Este esconseguir esta acomodación, que es el objetivo final. Este es-
fuerzo ha permitido ver la "fibra» del proyectista, y su fuerte personalidad empapar hasta los mínimos requisitos del programa inicial que le fue presentado.

Y así le vemos esforzándose en dar organicidad a dos elementos, tan distintos como el almacén y su administración. en atemperar las realizaciones de la fachada y el color de la misma con la necesidad de propaganda, y, en fir, en atenerse al funcionamiento y condicionarlo estéticamente.

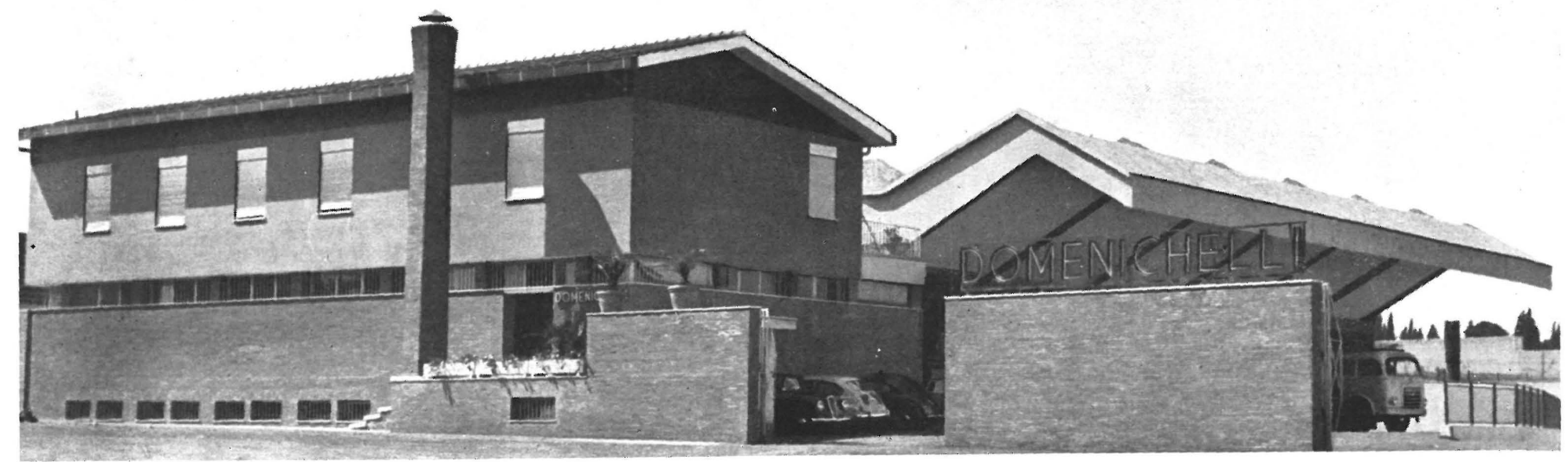


No se trata, pues, de ver si su intención y su forma de creación es legítima. Para juzgarla harán falta más elementos de juicio. Lo que importa destacar, en su justa medida, es la superación de algunas contingencias formales y la busca de un nuevo "clasicismo" de nuestros elementos estáticos como sustitución de las antiguas columnas vitruvianas.

\section{Descripción de la obra}

El cuerpo central y anexos del edificio, depósito de mercancias en tránsito, se pueden subdividir en tres partes completamente diferenciadas: el depósito propiamente dicho, las oficinas y los accesos a los muelles de carga de la planta baja y de la segunda planta.

La obra se cimentó sin dificultad alguna; su estructura es de hormigón armado, a excepción de la fachada principal, chime- nea y algunos detalles, que se han construído con Pábrica de ladrillo.

El depósito tiene dos plantas, una de ellas en semisótano, a la que se accede directamente por una linea ferroviaria y dos rampas, una de entrada y otra de salida, que vienen de la planta superior. A los muelles de carga y descarga de esta planta tienen acceso los camiones y vagones ferroviarios. En esta planta se han levantado una serie de pilares para sostener la planta superior.

Sobre la planta inferior, equipada con una grúa pórtico montacargas que la une con la superior, se ha construido la segunda planta, que forma una gran nave corrida y sin soportes intermedios, en la que el solo obstáculo que existe es el hueco del montacargas. Esta segunda planta se ha formado y cubierto por un procedimiento bastante significativo.

\section{planta}

\section{carga.}

-Nivel del piso de

2.-Grủa pórtico.

3.-Báscula.

4.-Montacargas.

5.-Lavadero de ca ches.

6.-Depósito.

7.-Compresor.

8.-Consumos.

9.-Aseos señoras.

10.-Aseos caballeros.

11.-Oficina.

12.-Dirección

13.-Centralita telefonica.

14.-Vestíbulo.

15.-Conserje.

16.-Surtidor de gasolina.

17.-Rampa de salida.

18.-Rampa de entrada.

19.-Hall.

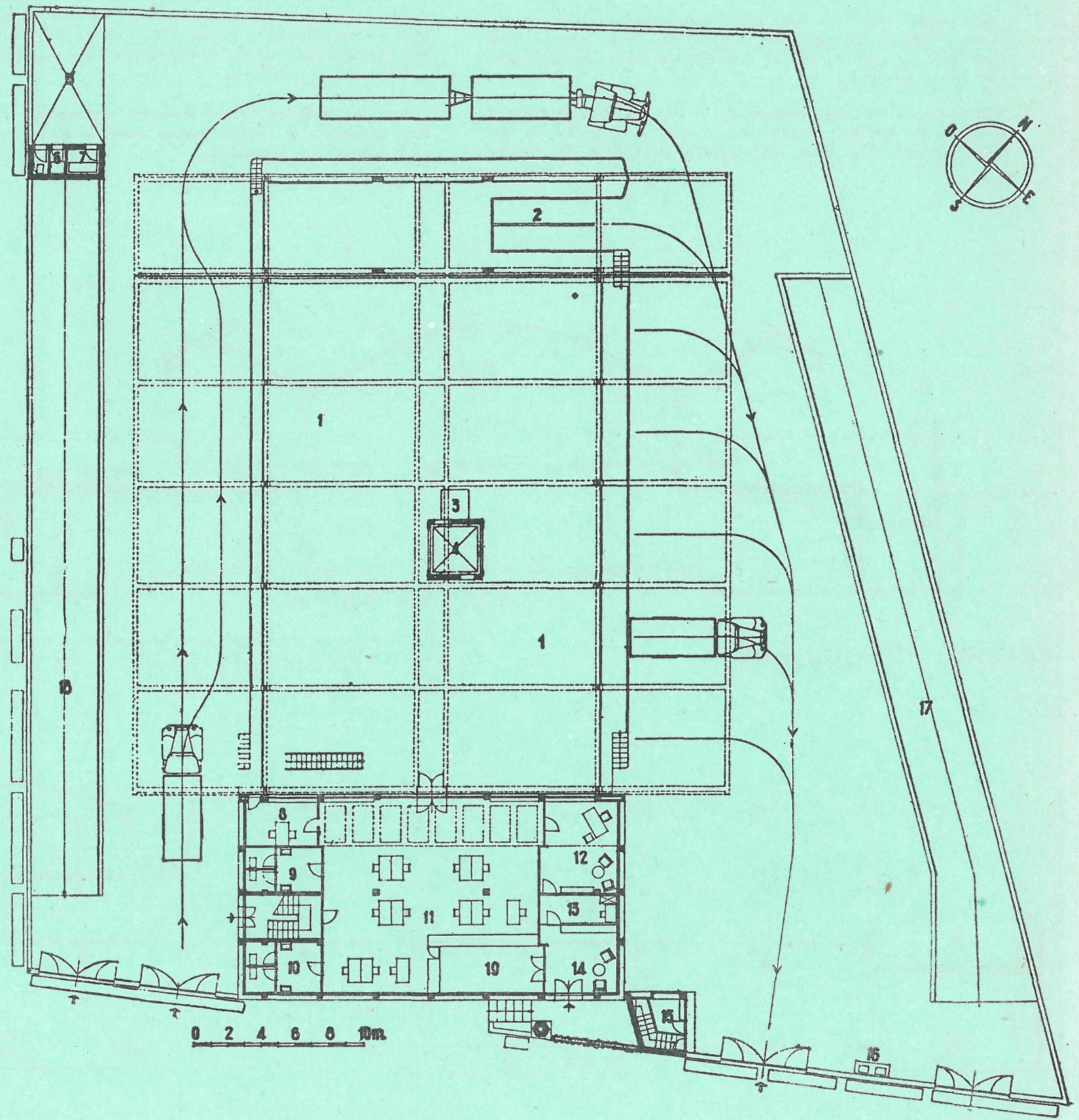


La cubierta se compone de siete cerchas formando pórtico de tres articulaciones, una en cada montante y la tercera en el centro del cabezal, cuya parte se ha reservado para el lucernario corrido que se extiende en toda la nave en la zona de su eje longitudinal.

Cada cercha, de hormigón armado, forma una superficie prismática de seis planos o faldones, cuya sección transversal es una línea poligonal. A la zona que cubre la nave le pertenecen dos faldones $/ y$ el lucernario, y al voladizo o marquesina que protege cada uno de los dos muelles de carga y descarga le corresponden otros dos faldones. Entre las marquesinas y el cuerpo de la parte central de la cubierta se han colocado los soportes, a los que se les ha dado una forma trapezoidal de gran altura.

Los soportes se han unido entre si con cuatro vigas perimetrales de cadena que arriostran rígidamente las cabezas de estos elementos. Estas vigas son de gran canto y poco espesor.

Los huecos entre las cerchas se han cerrado con losas delgadas y ligeras, pintadas por la cara que da al interior para contrastar en colorido con el gris del hormigón de los miembros de la estructura.

Debido a la superficie plegada de la cubierta y a los grandes voladizos de las marquesinas que cubren los muelles, la cubierta presenta una gran resistencia a los efectos del viento; pero se ha dispuesto de tal forma, que, con su armazón ligero estructural, estos efectos se contrarrestan fácilmente y dentro de una estabilidad perfecta.

Los nervios que constituyen las cerchas sobresalen exterior interiormente, con lo que se consigue un efecto muy agradable a la vista.

Adosado, al cuerpo del depósito se levanta el edificio de dos plantas, que constituye el departamento administrativo y sector de la explotación comercial. La fachada de este edificio, con su chimenea de fábrica de ladrillo, de sección hexagonal, que logra un gracejo arquitectónico, es sobria de línea y armoniza con el conjunto.

Los accesos, vía ferroviaria y puente grúa son complementos indispensables, de gran importancia en una explotación que, como ésta, el transporte, carga y descarga de mercancias tienen un interés vital. Para proyectar y disponer la circulación alrededor de las dos plantas del depósito, se han tenido que estu diar y dar solución a varios problemas de circulación, escracio, tipo de vehículos. altura y disposición de los muelles de carga y descarga de mercancías.

Para los servicios de conservación, reparaciones y lavabos se han habilitado ias partes menos sensibles al funcionalismo de este depósito de mercancías.

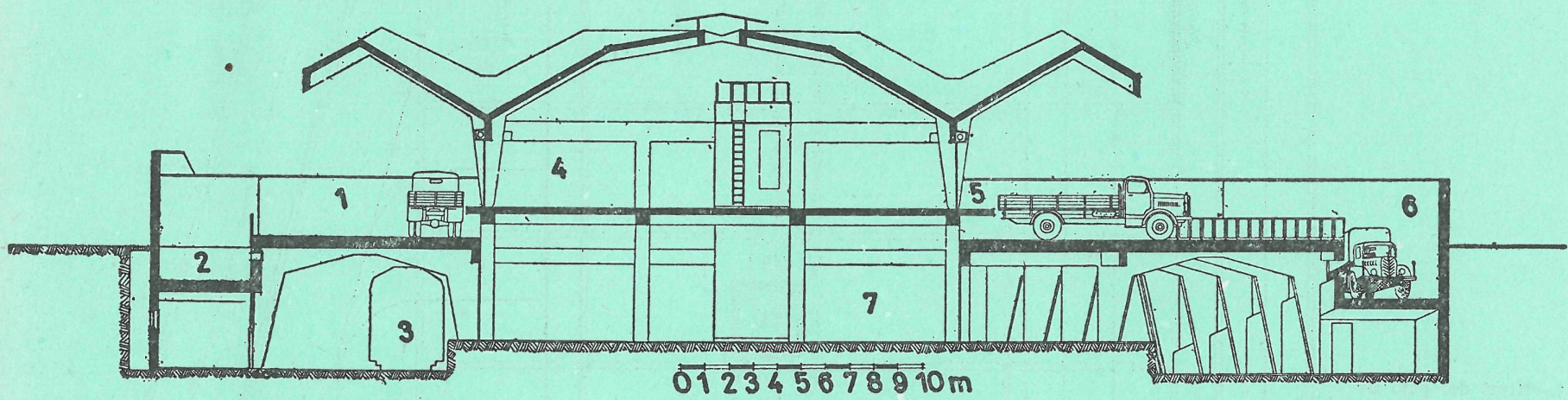

sección longitudinal

1. Muelle de carga y descarga.-2. Rampa de acceso.-3. Vía férrea.-4. Planta superior.-5. Muelle de carga.-6. Rampa de acceso.-7. Planta baja.

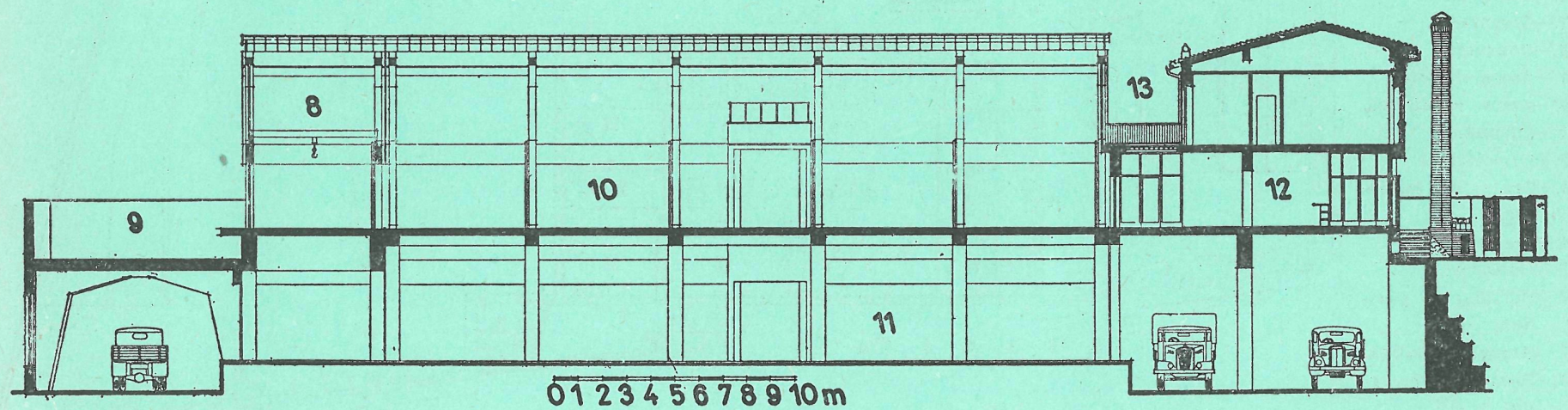

sección transversal
8. Grúa pórtico.-9. Muelle de carga.-10. Planta superior.-11. Planta baja.12. Oficina.-13. Paso al almacén. 

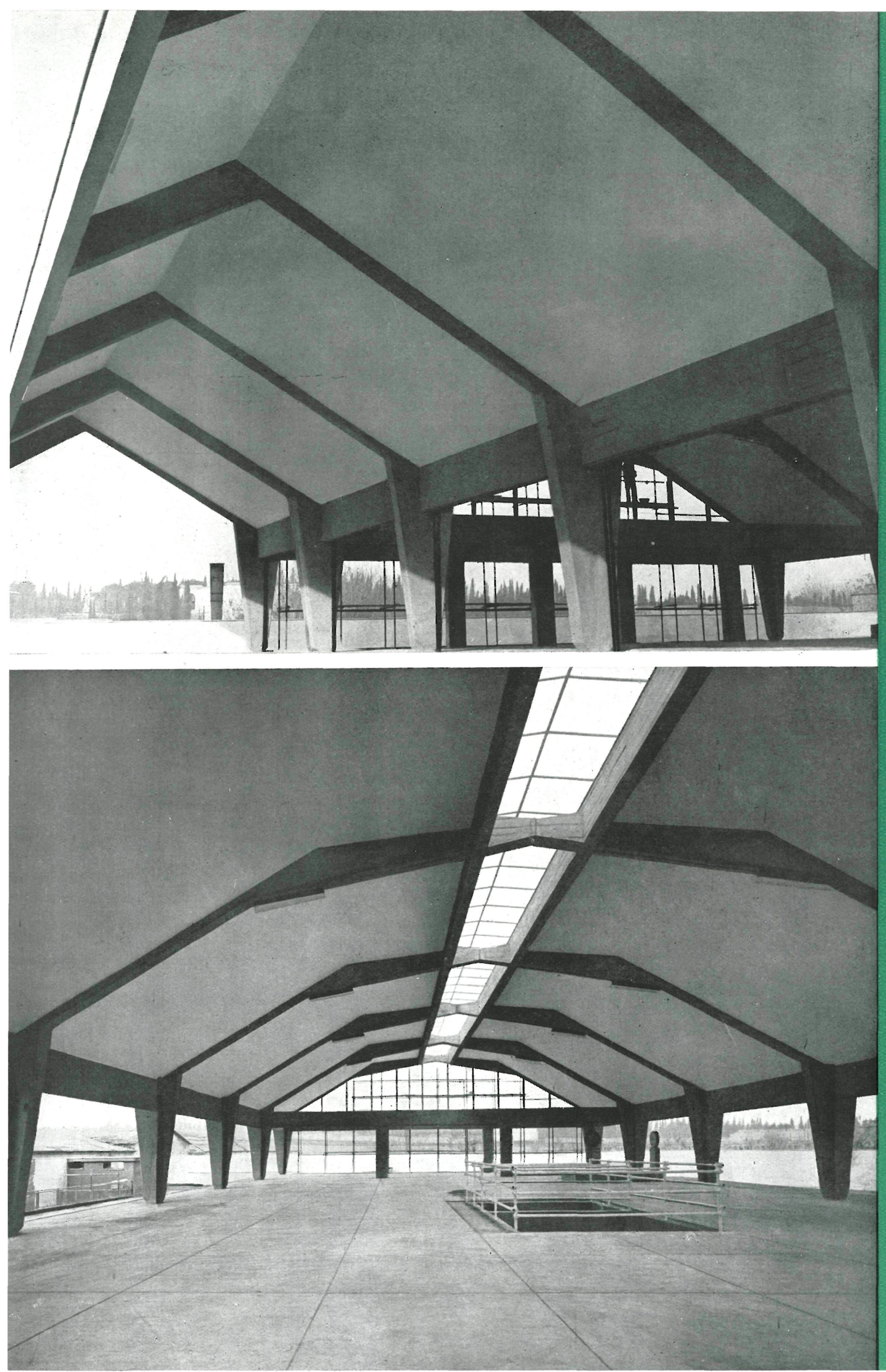